\title{
College English Flipped Classroom in Applied Undergraduate Colleges Based on Rain Classroom
}

\section{Liu Weiwei}

\author{
Basic Teaching Department, Shandong Huayu University of Technology, Dezhou, Shandong, China
}

Keywords: rain classroom; flipped classroom; teaching mode

\begin{abstract}
To meet the information needs of flipped classroom, the rain classroom was developed. The threshold of information technology was low, the function was strong, and the operation was simple. It provided a convenient path for the implementation of flipped classroom. The concept of the rain classroom and flipped classroom was elaborated. The flipped classroom teaching mode of the rain classroom was studied. The rain classroom application was studied and summarized in the model of college English flipped classroom. The results showed that the rain classroom ensured the effective interaction between teachers and students in pre-class preparation, classroom teaching and after-school review. Therefore, this method not only improves the quality of teaching, but also cultivates students' self-learning habits and abilities. It is of great significance to apply the rain classroom to the college English flipped classroom.
\end{abstract}

\section{Introduction}

The flipped classroom is a new teaching model in the current information age to meet educational needs. In this mode, informational methods such as micro-courses and MOOCs are used to realize the learning and internalization of knowledge, which satisfies the educational concept of current mobile learning and autonomous learning. At the same time, in the traditional classroom, the one-time and irreversible shortcomings of transferring knowledge were solved. It is trusted by more and more scholars at home and abroad [1]. However, MOOC and micro-course development have higher requirements for information technology literacy. At the same time, students need a software platform as a support during the learning process. These factors have had a certain impact on the reform of the teaching of the flipped classroom. In this context, the rain classroom came into being. Because of its low information technology threshold, strong function and easy operation, the reform and implementation of the flipped classroom is more convenient and efficient [2].

Based on the theoretical level and the practical level, the literature analysis method, the action research method, the questionnaire survey method and other methods are used to construct the college English flipped classroom teaching mode based on the rain classroom. In addition, its application effects are further explored.

\section{Theories}

\subsection{Flipped classroom}

The development of the flipped classroom can be summarized as a process from one point to the next. In the beginning, to solve the problem that individual students are delayed in learning due to their own physical reasons or other special reasons, some teachers use the method of recording teaching videos to explore teaching in a small scope [3]. By 2011, the establishment of the Khan Academy was a major turning point for the flipped classroom. Its degree of understanding and acceptance in the world has been greatly improved.

Compared with traditional teaching, the main difference is that in the flipped classroom, students need to learn the basics before class. Students use the online teaching videos and other related materials published by the teachers to conduct independent learning and complete the 
corresponding practice tests [4]. The classroom mode is to use the teacher-student interaction to subdivide the difficult knowledge, to improve the students' ability to think and use the knowledge they have learned to solve practical problems [5]. In short, the main difference between the flipped classroom and traditional teaching is the need to use information technology to complete the knowledge transfer before class. The understanding and acceptance of knowledge is accomplished through the interaction of teachers and students in the class.

\subsection{Rain classroom}

Rain Class is a new type of wisdom teaching tool developed jointly by Tsinghua University and Xuetang Online. It conducted a small-scale public beta in February 2016 and officially released in September 2016 [6]. Rain Class introduces advanced information technology in PPT and WeChat. The online virtual classroom and the offline physical classroom are connected efficiently, thus ensuring effective interaction between teachers and students in pre-class preparation, classroom teaching and after-school review. While improving the quality of teaching, students' self-learning habits and abilities are strengthened.

The rain classroom has many advantages, including easy operation, interactive intelligence, and panoramic recording. The collection of information data in the rain classroom covers all the processes before the class - during the class - after class. Students' pre-class preparations are clearly and accurately recorded. Pre-study videos, puzzles, and lecture content are told to students. The completion rate and accuracy of students after homework were tested [7]. Through the panoramic recording of learning behaviours, most of the learning process can be accurately restored, which is beneficial to the conversion of teaching activities from "experience-driven" to "data-driven" [8].

\section{Methodology}

\subsection{Teaching design of the flipped classroom}

When dividing the teaching process of the flipped classroom, it is roughly divided into three stages: pre-class, in-class and after-class. The three stages promote each other. Taking the example of Five Famous Symbols of American Culture in the third volume of the New Vision College English Reading and Writing Course (Second Edition), the teaching design of the flipped classroom was concretely displayed.

The pre-class preparation stage: According to the task list issued by the teacher, the students conduct self-study through the network and present their own problems in the discussion forum of the learning platform. The teacher then sets the difficulty of classroom teaching according to the students' problems. The teaching arrangements for the pre-class preparation stage are shown in Table 1:

Table 1 Teaching arrangements in the pre-class preparation stage

\begin{tabular}{|l|l|}
\hline \multicolumn{2}{|c|}{ Unit 4 Five Famous Symbols of American Culture } \\
\hline $\begin{array}{l}\text { Teaching } \\
\text { objectives }\end{array}$ & $\begin{array}{l}\text { Learn key words and phrases; learn basic information about five cultural } \\
\text { symbols }\end{array}$ \\
\hline Video content & $\begin{array}{l}\text { Text and new words explain; expand the information of five cultural } \\
\text { symbols }\end{array}$ \\
\hline $\begin{array}{l}\text { Task list } \\
\text { content }\end{array}$ & $\begin{array}{l}\text { Read the text; watch the video; answer questions related to the content of the } \\
\text { text; participate in the discussion }\end{array}$ \\
\hline
\end{tabular}

The consolidation phase in the class: Classroom learning is divided into two stages: answering questions and practicing classes. During the Q\&A session, the teacher understands the students' mastery of the text content through questioning and focuses on the difficult points. The teaching arrangements for the Q\&A session in the consolidation phase are shown in Table 2: 
Table 2 Teaching arrangement for answering questions in the consolidation phase of the class

\begin{tabular}{|l|l|}
\hline \multicolumn{2}{|c|}{ Unit 4 Five Famous Symbols of American Culture } \\
\hline Teaching objectives & Test students' self-learning; understand the text \\
\hline Classroom activities & $\begin{array}{l}\text { Classroom testing of preview content; teacher questions; teacher } \\
\text { explanation }\end{array}$ \\
\hline
\end{tabular}

Practice classes are designed to expand language knowledge and skills. It includes reading exercises for extracurricular materials and writing exercises based on the structure of the text. The teaching arrangements for the practice session in the consolidation phase are shown in Table 3:

Table 3 Teaching arrangements for the practice session in the consolidation phase of the class

\begin{tabular}{|l|l|}
\hline \multicolumn{2}{|c|}{ Unit 4 Five Famous Symbols of American Culture } \\
\hline Teaching objectives & Consolidate vocabulary; deepen the theme; expand the practice \\
\hline Language courses & $\begin{array}{l}\text { Group discussion; look at the picture to guess the word; translate } \\
\text { the Chinese summary of the text }\end{array}$ \\
\hline Development class & $\begin{array}{l}\text { Watch the video, practice dictation; follow the text to practice } \\
\text { writing }\end{array}$ \\
\hline
\end{tabular}

Summary stage after class: The teacher evaluates the usual grades based on the student's performance at each stage. The proportion of the usual grades in the total score should be greater than the final grade. The sample unit's usual scores and methods are shown in Table 4:

Table 4 Example unit usual score rating criteria and method

\begin{tabular}{|c|c|c|c|}
\hline \multicolumn{4}{|c|}{ Unit 4 Five Famous Symbols of American Culture } \\
\hline Scoring project & Basic requirements & $\begin{array}{l}\text { Percentage of } \\
\text { usual grades }\end{array}$ & Evaluation method \\
\hline $\begin{array}{l}\text { Network platform } \\
\text { resource learning }\end{array}$ & $\begin{array}{l}\text { Preview completed; complete } \\
\text { viewing }\end{array}$ & $20 \%$ & Platform scoring \\
\hline Q\&A discussion & $\begin{array}{l}\text { Actively participate in the } \\
\text { discussion }\end{array}$ & $5 \%$ & Platform scoring \\
\hline Classroom test & Pass the exam & $10 \%$ & Platform scoring \\
\hline $\begin{array}{l}\text { Classroom } \\
\text { performance }\end{array}$ & $\begin{array}{l}\text { Actively answer questions } \\
\text { and participate in class } \\
\text { activities }\end{array}$ & $10 \%$ & Teacher evaluation \\
\hline Group display & $\begin{array}{l}\text { Rich in content; language } \\
\text { standards; fluent in } \\
\text { explanation }\end{array}$ & $15 \%$ & Peer review \\
\hline Word contest & Pass the exam & $10 \%$ & $\begin{array}{l}\text { Independent } \\
\text { evaluation }\end{array}$ \\
\hline $\begin{array}{l}\text { Translation } \\
\text { practice }\end{array}$ & $\begin{array}{l}\text { Combination of the original } \\
\text { text; sentence smooth }\end{array}$ & $10 \%$ & Teacher evaluation \\
\hline Dictation practice & Correct words & $5 \%$ & $\begin{array}{l}\text { Independent } \\
\text { evaluation }\end{array}$ \\
\hline Writing practice & $\begin{array}{l}\text { Meet the grammatical } \\
\text { requirements }\end{array}$ & $5 \%$ & Peer review \\
\hline Reflective record & $\begin{array}{l}\text { The text summary is accurate } \\
\text { and profound }\end{array}$ & $10 \%$ & Teacher evaluation \\
\hline
\end{tabular}

\subsection{Application of teaching mode in rain classroom and flipped classroom}

According to the teaching philosophy of the flipped classroom and the functional characteristics of the rain classroom, an undergraduate college was selected as the experimental object, and the teaching practice of the flipped classroom based on the rain classroom was carried out. Its teaching 
mode is shown in Figure 1:
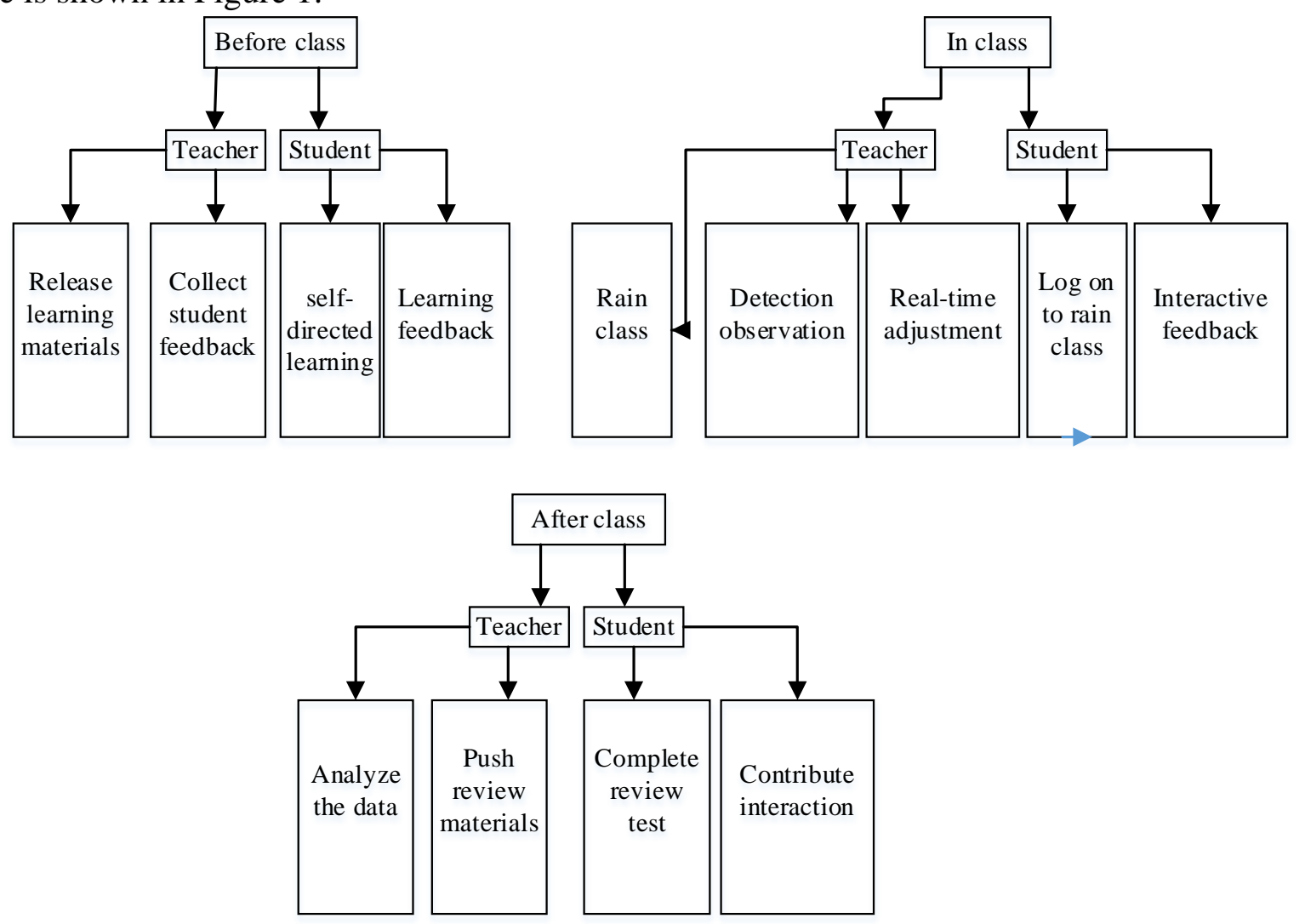

Figure 1 The flipped classroom teaching model of rain classroom

Pre-class mode: Teachers plan their teaching goals first. Then, according to the teaching objectives, the corresponding teaching plan is designed. The teacher prepares the pre-study course, including the task list, the guiding case, the knowledge point explanation and the resources expansion, and publishes it to the rain classroom. Students use WeChat to realize the new tasks of the rain classroom and promote the cultivation of students' independent learning ability. Through the preparation of courseware, students use the "student feedback" function to report doubts, problems and interests in the preview process in a timely manner. Data such as student preparation time and number of views are recorded simultaneously by the rain classroom. It is convenient for teachers to have a comprehensive understanding of the students' learning status and provides corresponding procedural evaluation basis.

In-class mode: Students can enter the corresponding rain classroom group to complete the classroom electronic attendance by scanning the QR code. With the rain classroom as a supplement, teachers realize synchronous and asynchronous "dual-channel teaching”. Synchronization refers to centralized teaching of difficult points, and asynchronous refers to deepening the understanding of PPT content and discussion of barrage. On the other hand, teachers can help students maintain their long-term attention and timely understand the classroom learning effects by setting the time detection test. Combined with the completion status of the test questions and the students' doubts through the barrage message, the rhythm and content of the classroom teaching are adjusted in time to achieve effective interaction.

After school mode: The PPT synchronization feature in the rain class makes it easy for students to review class content after class and to achieve after-school review. The Rain Class is used to post the after-school review function, which is more convenient and faster. At the same time, the mobility of learning and the efficient use of fragmentation time are realized. The rain class records the students' learning in the class and transmits them to the teacher's mobile phone in the form of after-school summary, which is convenient for the teacher to understand the students' learning acceptance and develop a targeted teaching strategy. At the same time, if the students still do not understand the teaching content, they can directly find relevant information on the Internet, or 
communicate with the teacher through the form of submission. It truly realizes the teacher-student interaction before class - in class - after the class.

\section{Results and Discussion}

After a semester based on the practice of the flipped classroom teaching in the rain classroom, a questionnaire survey was conducted on the implementation effect of the rain classroom.

\subsection{The effect of rain classroom on teaching quality}

A total of 325 questionnaires were distributed and 320 were collected. According to the survey results, 302 people think that the rain classroom is higher than the traditional classroom teaching, accounting for $94.37 \%$ of the total number. It can be inferred that most students support the rain classroom to improve the quality of teaching.

\subsection{Analysis of the main functions of the rain classroom}

To better play the role of the rain classroom, improve the quality of teaching and comprehensively and accurately understand the students' learning needs, a small-scale investigation was conducted on the main functions of the rain classroom. Among the functions presented, 84.1\% of the students expressed their preference for the "mobile phone synchronization PPT" function, which has a great connection with the class size of the experimental class. In teaching, more attention should be paid to the "asynchronous learning" needs of students due to different learning abilities. $47.9 \%$ of the students said that they liked the pre-study function of the rain class. This shows that students have basically formed a pre-study habit of mobile pre-class and self-study, but the initiative still needs to be improved.

\section{Conclusions}

In the English class, the teaching practice of the flipped classroom based on the rain classroom was carried out. This new wisdom teaching tool was promoted to various classroom teaching. A survey was conducted among the students tested for this problem. The survey results show that $90.9 \%$ of the students are supportive and hope to continue to apply the rain classroom to the teaching of other courses. It can be seen that under the background of information-based teaching reform, the rain classroom has a good development prospect.

\section{Acknowledgement}

This is the result of the research phase of the "An Empirical Study of the Flipping Classroom Teaching Method Based on the Rain Classroom Teaching Platform in English Teaching in Higher Vocational Colleges” (Project Code: 2017306) and “An Empirical Study of the Flipping Classroom Teaching Method in the Background of "Rain Classroom” in College English Teaching in Applied Undergraduate Colleges” (Project Code: BYGW2017001).

\section{References}

[1] Hanson J. Surveying the experiences and perceptions of undergraduate nursing students of a flipped classroom approach to increase understanding of drug science and its application to clinical practice. Nurse Education in Practice, 2016, 16(1), pp. 79-85.

[2] Enfield J. Looking at the Impact of the Flipped Classroom Model of Instruction on Undergraduate Multimedia Students at CSUN. Techtrends, 2013, 57(6), pp. 14-27.

[3] Fatima S S, Arain F M, Enam S A. Flipped classroom instructional approach in undergraduate medical education. Pakistan Journal of Medical Sciences, 2017, 33(6), pp. 1424-1428.

[4] Hung H. Design-Based Research: Redesign of an English Language Course Using a Flipped 
Classroom Approach. Tesol Quarterly, 2017, 51(1), pp. 180-192.

[5] Liu D. The Reform and Innovation of English Course: A Coherent Whole of MOOC, Flipped Classroom and ESP. Procedia - Social and Behavioral Sciences, 2016, 232, pp. 280-286.

[6] Suo, Jia Hou, Xiuying. A Study on the Motivational Strategies in College English Flipped Classroom. English Language Teaching, 2017, 10(5), pp. 62.

[7] Sam D P. Natural Approach of Teaching English Language on a Flipped Classroom Platform to Tertiary Level Engineering Learners. 2016, 14(12), pp. 13-18.

[8] Yan-ru. On the Feasibility of WeChat-based Flipped Classroom for the Teaching of English Phonetics. Overseas English, 2017(5), pp. 472-474. 